\title{
Smoking behaviors before and after implementation of a smoke-free legislation in Guangzhou, China
}

Xiaohua Ye ${ }^{1}$, Sidong Chen ${ }^{1}$, Zhenjiang Yao ${ }^{1}$, Yanhui Gao ${ }^{1}$, Ya Xu', Shudong Zhou', Zhengwei Zhu², Liang Wang $^{3}$ and Yi Yang ${ }^{1 *}$

\begin{abstract}
Background: According to the partial smoke-free legislation implemented on 1 September 2010 in Guangzhou, China, smoke-free did not cover all indoor areas. Some places have a full smoking ban (100 \% smoke-free), other places have a partial smoking ban, and homes have no ban. This study aimed to compare the smoking behaviors before and after implementation of a smoke-free legislation.

Method: A repeated cross-sectional survey was conducted on smoking-related behaviors with a total of 4,900 respondents before, and 5,135 respondents after the legislation was instituted. For each wave of the survey, a three-stage stratified sampling process was used to obtain a representative sample. Pearson's Chi-square test was used to determine differences of smoking prevalence and quit ratio between the two samples. Logistic regression models were used to examine the associations of a smoke-free legislation with smoking behaviors.

Results: The overall daily smoking rate declined significantly from $20.8 \%$ to $18.2 \%(p<0.05)$, especially among those aged 15-24 years. The quit ratios increased significantly (from $14.5 \%$ to $17.9 \%$ ), but remained low among 15-44 year olds. The overall self-reported smoking behaviors in locations with a full smoking ban decreased significantly from $36.4 \%$ to $24.3 \%$ with the greater drops occurring in cultural venues, public transport vehicles, and government offices. Smoking in places with partial smoking bans remained high (89.6 \% vs. $90.4 \%$ ), although a slight decrease was observed in some of these areas. The implementation of a smoke-free legislation did not lead to more smoking in homes (91.0 \% vs $89.4 \%$ ), but smoking in homes remained high.

Conclusions: These findings highlight the urgent need for a comprehensive smoke-free legislation covering all public places in Guangzhou, simultaneously educational interventions and campaigns promoting voluntary changes in home smoking need to occur.
\end{abstract}

Keywords: Smoke-free, Tobacco control, Smoking

\section{Background}

Tobacco use substantially increases the risk of dying from cancers, heart diseases, stroke and chronic respiratory diseases, and has been the second leading risk factor for deaths worldwide [1]. It is noteworthy that tobacco use is increasing in many low- and middle-income countries [2]. By 2030, if current patterns of use persist, tobacco will kill more than 8 million people worldwide

\footnotetext{
* Correspondence: yangyigz@163.com

${ }^{1}$ Department of Epidemiology and Biostatistics, School of Public Health, Guangdong Pharmaceutical University, Guangzhou, China

Full list of author information is available at the end of the article
}

each year, and $80 \%$ of these premature deaths will occur in low- and middle-income countries [2]. One such country, the world's largest producer, consumer and victim of tobacco, is China. A recent study indicated that China was home to 301 million smokers $(45.5 \%$ of the world's smokers), only $16 \%$ of current smokers were looking to quit in the coming year [3]. Approximately one million people die every year due to direct or indirect tobacco-related deaths [4].

The findings from studies conducted in several countries indicate that smoke-free legislations can improve indoor air quality, reduce tobacco use and decrease 
hospital admissions attributed to acute coronary syndrome [5-8]. Although so far no national smoke-free law exists in China, Guangzhou was one of the earliest cities to implement a partial smoke-free legislation, beginning September 1, 2010. According to the legislation, smoke-free did not cover all indoor areas. Some places (including cultural venues, public transportation vehicles, government offices, commercial venues, medical facilities, schools, and stadiums) have a full smoking ban (100\% smoke-free, without designated smoking rooms), other places (including workplaces, restaurants, hotels, cafes, bars, nightclubs, amusement parks, and waiting rooms of transportation vehicles) have a partial smoking ban (with designated smoking rooms), and homes have no smoking ban. Although Guangzhou did not adopt a $100 \%$ smoke-free policy, the partial smoke-free legislation was the most strict tobacco control policy in China at that time.

Even though a smoke-free legislation can be a powerful public health intervention, little is known about the impacts of a smoke-free legislation on smoking behaviors in full, partial and no smoking ban places in Guangzhou, China. Additionally, before the legislation was implemented, there was concern that people might transfer their smoking from public places to their homes. Therefore, the present study aimed to address the following three questions: (1) Were there differential associations of a smoke-free legislation with smoking behaviors in full and partial smoking ban places in Guangzhou, China? (2) Would smokers transfer their smoking behaviors from public places and workplaces to their homes? (3) Did indicators of smoking prevalence decrease and quit ratios increase in Guangzhou after the legislation was implemented?

\section{Methods \\ Sampling design}

Two epidemiological, observational and cross-sectional surveys were conducted in Guangzhou, China. The methods of the survey are described in detail elsewhere [9]. Briefly, a three-stage stratified sampling process was employed to obtain an independent, representative sample. The field work for the baseline survey was undertaken in May 2009, before the implementation of the smoke-free legislation. The evaluation survey was conducted in May 2011, 9 months after implementation of the smoke-free legislation. A total of 4,930 participants were interviewed in the baseline survey, and 5,156 participants were interviewed in the evaluation survey.

\section{Study variables}

The primary outcome variables were smoking prevalence, quit ratio, and smoking behaviors in different kinds of venues. Accordingly, the survey instrument contained three major sections: 1) smoking prevalence, 2) quit ratio and 3) smoking behaviors. To determine the prevalence of smoking, individuals were asked if they were current smokers (a person who has smoked daily or occasionally in the last 30 days for at least 6 months) or former smokers (a person who has a history of smoking for at least 6 months and currently has stopped). To assess smoking behaviors, current smokers were asked a series of questions to determine their travel history (i.e. cultural venues, public transportation vehicles, government offices, commercial venues, medical facilities, schools, stadiums, workplaces, restaurants, hotels, cafes, bars, nightclubs, amusement parks, waiting rooms of transportation vehicles and homes) for the past two weeks and if smoking had occurred at that particular location. To evaluate quitting behaviors, the quit ratio was estimated by taking the ratio of the number of former smokers to the number of ever smokers [10]. The main predictor variable was the implementation of the smoke-free legislation.

\section{Data collection and quality control}

Interviewers were enrolled voluntarily from third- and fourth-year undergraduate students in the School of Public Health of Guangdong Pharmaceutical University, China. All interviewers were trained to ensure that the operation procedures were identical across all areas. After obtaining informed consent verbally, eligible respondents were asked to complete a face-to-face survey by the trained interviewers.

\section{Data analysis}

All data were entered in duplicate into the EpiData version 3.1 database, and data entry screens were used to revise incorrect entries. Descriptive statistics were conducted for the two samples. The data from smoking prevalence and quit ratios were examined by sex and age, and differences between the two samples were determined using the Pearson's chi-square test. Separate logistic regression models were used to examine the associations of a smoke-free legislation with smoking behaviors. The two-sided p-value for statistical significance was defined as $p<0.05$. To account for sampling design and weight in the estimation procedures, statistical analyses were conducted with weighted data, except for those otherwise specified. All statistical analyses were conducted using STATA version 13.0 (StataCorp LP, College Station, Texas, USA).

\section{Ethical approval}

The study was approved by the ethics committee of Guangdong Pharmaceutical University, and this survey was qualified as involving no risks to participants. A verbal informed consent regarding the goals of the study 
and the willingness to participate in the study was given by the participants.

\section{Results}

\section{Demographic characteristics}

In the baseline survey conducted in 2009 (before implementation of the smoke-free legislation), a total of 5409 participants were interviewed, of whom 4930 (91.1\%) were willing to participate and 4900 (90.6\%) provided complete data. In the evaluation survey conducted in 2011 (after implementation of the smoke-free legislation), a total of 5614 participants were interviewed, of whom 5156(91.8 \%) were willing to participate and 5135(91.5\%) provided complete data. The demographic characteristics were similar in both samples (Table 1 ) and no significant differences in gender $(p=0.255)$ and age $(p=0.313)$ were detected. Notably, both samples represent the adult population in Guangzhou sufficiently, with the exception of a significant oversampling of females aged $45-54$ years in both samples and females aged 55-64 years only in the 2011 sample (Table 2). This discrepancy was adjusted by applying the weighing techniques.

\section{Smoking prevalence}

Smoking prevalence, stratified by sex and age, is reported in Table 3 for both samples. The overall daily smoking rate decreased significantly after implementation of the smokefree legislation (from $20.8 \%$ in the baseline survey to $18.2 \%$ in the evaluation survey; $p<0.01$ ). The reduction in daily smoking rate achieved statistical significance among 15-24 year olds, also within age group, significant reductions in smoking were observed in males (from $27.1 \%$ to $20.4 \% ; p=0.016$ ) and females (from $2.2 \%$ to $0 \%$;

Table 1 Demographic characteristics of all participants according to survey waves ((baseline vs evaluation survey), in Guangzhou, China

\begin{tabular}{|c|c|c|c|c|c|c|c|}
\hline \multirow[t]{2}{*}{ Variables } & \multirow[t]{2}{*}{ Number } & \multicolumn{2}{|c|}{ Baseline survey } & \multicolumn{2}{|c|}{ Evaluation survey } & \multirow[t]{2}{*}{$x^{2}$} & \multirow[t]{2}{*}{$p$} \\
\hline & & $n_{1}$ & $\%$ & $\mathrm{n}_{2}$ & $\%$ & & \\
\hline \multicolumn{8}{|l|}{ Gender } \\
\hline Male & 4418 & 2129 & 43.5 & 2289 & 44.6 & 1.29 & 0.255 \\
\hline Female & 5617 & 2771 & 56.5 & 2846 & 55.4 & & \\
\hline \multicolumn{8}{|l|}{ Age(years) } \\
\hline $15-24$ & 1713 & 816 & 16.6 & 897 & 17.5 & 5.93 & 0.313 \\
\hline $25-34$ & 1921 & 926 & 18.9 & 995 & 19.4 & & \\
\hline $35-44$ & 2060 & 1013 & 20.7 & 1047 & 20.4 & & \\
\hline $45-54$ & 2022 & 997 & 20.3 & 1025 & 20.0 & & \\
\hline $55-64$ & 1238 & 589 & 12.1 & 649 & 12.6 & & \\
\hline $65+$ & 1081 & 559 & 11.4 & 522 & 10.1 & & \\
\hline
\end{tabular}

All estimates are unweighted
$n$, number of participants in both surveys; $n_{1}$, number of participants in the baseline survey; $\mathrm{n}_{2}$, number of participants surveyed in the evaluation survey; $\%$, the proportion of participants surveyed
Table 2 Demographic characteristics of samples according to survey waves (baseline vs evaluation survey) and population according to a census in 2009 in Guangzhou, China

\begin{tabular}{|c|c|c|c|}
\hline Gender and age & $\begin{array}{l}\text { Baseline } \\
\text { survey } n_{1}(\%)\end{array}$ & $\begin{array}{l}\text { Evaluation } \\
\text { survey } n_{2}(\%)\end{array}$ & $\begin{array}{l}2009 \text { Population }^{\mathrm{a}} \\
\mathrm{n}(\%)\end{array}$ \\
\hline \multicolumn{4}{|l|}{ Males } \\
\hline $15-24$ years & $433(8.8)$ & $496(9.7)$ & 722862 (10.6) \\
\hline 25-34 years & 409 (8.4) & $522(10.2)$ & $660577(9.7)$ \\
\hline $35-44$ years & $427(8.7)$ & $496(9.7)$ & $696426(10.2)$ \\
\hline $45-54$ years & $363(7.4)$ & $342(6.7)$ & $601859(8.8)$ \\
\hline $55-64$ years & $229(4.7)$ & $220(4.3)$ & 390965 (5.7) \\
\hline $65+$ years & $272(5.5)$ & $212(4.1)$ & $364886(5.3)$ \\
\hline \multicolumn{4}{|l|}{ Females } \\
\hline $15-24$ years & $383(7.8)$ & $401(7.8)$ & $667648(9.8)$ \\
\hline 25-34 years & $517(10.5)$ & $473(9.2)$ & $631947(9.3)$ \\
\hline $35-44$ years & $586(12.0)$ & $551(10.7)$ & $693369(10.2)$ \\
\hline $45-54$ years & $634(12.9)$ & $\underline{683(13.3)}$ & $573130(8.4)$ \\
\hline $55-64$ years & $360(7.4)$ & $429(8.3)$ & $399627(5.8)$ \\
\hline $65+$ years & $287(5.9)$ & $310(6.0)$ & $425490(6.2)$ \\
\hline
\end{tabular}

All estimates are the proportion of participants surveyed and unweighted Significant difference in baseline survey and evaluation survey samples from the 2009 population is highlighted by boldfacing and underlining them $(p<0.05$ level)

${ }^{\text {aS }}$ ource from Guangzhou Public Security Bureau

$p=0.003)$. The change for occasional smokers remained relatively constant and was not statistically significant ( $1.2 \%$ in baseline survey vs $1.1 \%$ in the evaluation survey; $p=0.706)$.

\section{Quit ratio}

After implementation of the smoke-free legislation, the quit ratio increased significantly in male smokers (from $14.4 \%$ to $17.2 \% ; p=0.028$; Table 3 ), and this increase was marked among 15-24, 25-34, and 65+ years old males. Of note, the quit ratio among 15-34 year old males increased because of increasing rates of former smokers and decreasing rates of ever-smokers, and the quit ratio among $65+$ year old males increased only because of increasing rates of former smokers. After implementation of the smoke-free legislation, the quit ratio increased more than three-folds in female smokers (from $14.3 \%$ to $46.7 \% ; p<0.001$; Table 3 ), and this increase was marked among $25+$ year old females. The quit ratio among 45-64 year old females increased because of increasing rates of former smokers and decreasing rates of ever-smokers, the quit ratio among 24-34 and 65+ year old females increased only because of increasing rates of former smokers, but the quit ratio among 35-44 year old females increased only because of decreasing rates of ever-smokers. However, the quit ratio remained low among 15-44 year old males and females. 
Table 3 Smoking prevalence (\%) among adults according to survey waves (baseline vs evaluation survey), in Guangzhou, China

\begin{tabular}{|c|c|c|c|c|c|c|c|c|c|c|}
\hline \multirow{2}{*}{$\begin{array}{l}\text { Age and } \\
\text { gender }\end{array}$} & \multicolumn{2}{|c|}{ Daily smoker } & \multicolumn{2}{|c|}{ Occasional smoker } & \multicolumn{2}{|c|}{ Former smoker } & \multicolumn{2}{|c|}{ Ever smoker } & \multicolumn{2}{|l|}{ Quit ratio } \\
\hline & Baseline & Evaluation & Baseline & Evaluation & Baseline & Evaluation & Baseline & Evaluation & Baseline & Evaluation \\
\hline Total & 20.8 & 18.2 & 1.2 & 1.1 & 3.7 & 4.2 & 25.6 & $\underline{23.5}$ & 14.5 & 17.9 \\
\hline $15-24$ years & 15.2 & $\underline{10.7}$ & 2.0 & 1.0 & 0.4 & 0.9 & 17.5 & 12.6 & 2.3 & $\underline{7.1}$ \\
\hline $25-34$ years & 19.3 & 16.4 & 1.4 & 1.1 & 1.4 & 2.5 & 22.1 & 20.0 & 6.3 & 12.5 \\
\hline $35-44$ years & 21.0 & 20.8 & 0.5 & $\underline{1.5}$ & 1.8 & 2.5 & 23.3 & 24.9 & 7.7 & 10.0 \\
\hline $45-54$ years & 28.4 & 29.6 & 1.0 & 1.0 & 7.1 & $\underline{4.9}$ & 36.4 & 35.5 & 19.5 & 13.8 \\
\hline 55-64 years & 27.4 & 26.2 & 0.5 & 0.8 & 8.6 & 9.7 & 36.4 & 36.7 & 23.6 & 26.4 \\
\hline $65+$ years & 17.2 & 12.2 & 1.2 & 0.7 & 16.3 & 18.6 & 34.8 & 31.4 & 46.8 & $\underline{59.2}$ \\
\hline Males & 37.4 & 34.3 & 2.0 & 1.9 & 6.6 & 7.5 & 45.7 & 43.6 & 14.4 & $\underline{17.2}$ \\
\hline $15-24$ years & 27.1 & $\underline{20.4}$ & 3.5 & 1.9 & 0.6 & 1.7 & 31.2 & $\underline{24.0}$ & 1.9 & $\underline{7.1}$ \\
\hline 25-34 years & 35.5 & 29.8 & 2.6 & 1.7 & 2.7 & 4.4 & 40.8 & 35.9 & 6.6 & 12.3 \\
\hline $35-44$ years & 37.9 & 41.4 & 0.9 & $\underline{2.7}$ & 3.3 & 4.9 & 42.1 & $\underline{48.9}$ & 7.8 & 10.0 \\
\hline $45-54$ years & 48.6 & 52.9 & 1.7 & 1.8 & 12.4 & 8.0 & 62.7 & 62.7 & 19.8 & 12.8 \\
\hline 55-64 years & 47.5 & 49.3 & 0.8 & 1.3 & 14.1 & 17.0 & 62.4 & 67.5 & 22.6 & 25.2 \\
\hline $65+$ years & 28.6 & 23.1 & 1.5 & 0.9 & 29.0 & 34.2 & 59.0 & 58.2 & 49.2 & $\underline{58.8}$ \\
\hline Females & 1.6 & $\underline{0.5}$ & 0.2 & 0.3 & 0.3 & $\underline{0.7}$ & 2.1 & 1.5 & 14.3 & $\underline{46.7}$ \\
\hline $15-24$ years & 2.2 & $\underline{0.0}$ & 0.4 & 0.1 & 0.0 & 0.0 & 2.6 & $\underline{0.1}$ & 0.0 & 0.0 \\
\hline 25-34 years & 0.6 & 0.6 & 0.0 & 0.4 & 0.0 & 0.3 & 0.7 & 1.3 & 0.0 & 23.1 \\
\hline $35-44$ years & 1.2 & 0.3 & 0.0 & 0.4 & 0.1 & 0.1 & 1.3 & 0.8 & 7.7 & 12.5 \\
\hline $45-54$ years & 2.0 & 0.8 & 0.0 & 0.1 & 0.2 & 0.9 & 2.2 & 1.8 & 9.1 & $\underline{50.0}$ \\
\hline 55-64 years & 1.2 & 0.4 & 0.0 & 0.3 & 1.3 & 1.6 & 2.5 & 2.3 & 52.0 & $\underline{69.6}$ \\
\hline $65+$ years & 4.2 & 2.3 & 1.0 & 0.6 & 1.9 & 4.4 & 7.1 & 7.2 & 26.8 & 61.1 \\
\hline
\end{tabular}

All estimates are weighted

Quit ratio, the ratio of former smokers to ever smokers

Significant difference between baseline and evaluation sample is highlighted by boldfacing and underlining them ( $p<0.05$ level)

\section{Smoking behaviors in different kinds of venues}

In places where the full smoking ban were implemented, the self-reported overall smoking behaviors decreased significantly (from $36.4 \%$ to $24.3 \% ; p<0.05$; Table 4 ). The largest impact was observed in both cultural venues (from $22.2 \%$ to $8.7 \%$; $p<0.05$ ) and public transport vehicles (from $10.7 \%$ to $4.2 \%$; $p<0.05$ ) with a $60.8 \%$ reduction. A significant decline also occurred in government offices (from $48.3 \%$ to $24.8 \%$; $p<0.05$ ) with a $48.7 \%$ reduction. Of note, smoking behaviors remained high in any types of partial smoking ban places (Table 4), and a significant decline was observed only in workplaces (from $78.8 \%$ to $64.5 \% ; p<0.05$ ), restaurants (from $85.3 \%$ to $75.1 \% ; p<0.05$ ), and hotels (from $83.4 \%$ to $75.6 \% ; p<$ $0.05)$. Although the smoke-free regulation did not cover in home environment, the legislation did not lead to more smoking behaviors in homes (91.0 \% in baseline survey vs $89.4 \%$ in evaluation survey; $p=0.138$; Table 4 ). It was noteworthy that smoking in homes remained high.

\section{Discussion}

After the implementation of the partial smoke-free legislation began in September 2010 in Guangzhou, China, the self-reported smoking behaviors reduced more significantly in full smoking ban places (from $36.4 \%$ to $24.3 \%)$ than in partial smoking ban places $(89.6 \%$ in the baseline survey vs $90.4 \%$ in the evaluation survey), and this legislation did not lead to more smoking in homes $(91.0 \%$ vs $89.4 \%)$. The daily smoking prevalence declined significantly (from $20.8 \%$ to $18.2 \%$ ), especially among 15-24 year olds, and the quit ratios increased significantly (from $14.5 \%$ to $17.9 \%$ ). But smoking in banned places and the home environment still remained high, and the quit ratios remained low.

Studies conducted in several countries have shown that smoke-free legislations can reduce smoking-related behaviors $[5-8,11,12]$. The reduction in smoking occurs, likely because the smoke-free legislation increases support for regulating smoking, reduces the social acceptability of smoking, limits opportunities for smoking, and leads to less socially cued smoking [12-14]. Moreover, there is evidence that the comprehensive smoke-free legislation (i.e., $100 \%$ smoke-free legislation, without designated smoking rooms) has a greater effect on reducing smoking behaviors than the partial smoke-free legislation $[15,16]$. This study found a significant reduction in 
Table 4 Self-reported smoking of current smokers in the last 2 weeks according to survey waves (baseline vs evaluation survey), in Guangzhou, China

\begin{tabular}{|c|c|c|c|c|c|c|c|}
\hline \multirow{2}{*}{$\begin{array}{l}\text { Extent of smoking restriction, } \\
\text { venues }\end{array}$} & \multicolumn{2}{|c|}{ Baseline survey } & \multicolumn{2}{|c|}{ Evaluation survey } & \multirow{2}{*}{$\begin{array}{l}\text { Reduction } \\
(\%)\end{array}$} & \multirow{2}{*}{$\begin{array}{l}\text { aOR(95\% Cl) for } \\
\text { smoking ban }\end{array}$} & \multirow[t]{2}{*}{$p$} \\
\hline & $\mathrm{n}_{1}$ & Smoking (\%) & $\mathrm{n}_{2}$ & Smoking (\%) & & & \\
\hline Full smoking ban & 763 & 36.4 & 839 & 24.3 & 33.2 & $0.56(0.38$ to 0.82$)$ & 0.022 \\
\hline Cultural venues & 168 & 22.2 & 194 & 8.7 & 60.8 & $0.34(0.17$ to 0.68$)$ & 0.022 \\
\hline Public transport vehicles & 582 & 10.7 & 698 & 4.2 & 60.8 & $0.38(0.20$ to 0.73$)$ & 0.023 \\
\hline Government offices & 165 & 48.3 & 158 & 24.8 & 48.7 & $0.35(0.13$ to 0.93$)$ & 0.044 \\
\hline Commercial venues & 584 & 15.8 & 723 & 7.6 & 51.9 & $0.42(0.16$ to 1.07$)$ & 0.057 \\
\hline Medical facilities & 210 & 21.5 & 236 & 14.0 & 34.9 & $0.58(0.26$ to 1.31$)$ & 0.102 \\
\hline Stadiums & 184 & 42.6 & 189 & 29.6 & 30.5 & $0.62(0.26$ to 1.46$)$ & 0.137 \\
\hline Primary/secondary schools & 213 & 21.2 & 193 & 19.8 & 6.6 & $1.08(0.34$ to 3.44$)$ & 0.813 \\
\hline Universities & 91 & 31.4 & 99 & 29.4 & 6.4 & $0.96(0.49$ to 1.86$)$ & 0.802 \\
\hline Partial smoking ban & 842 & 89.6 & 873 & 90.4 & -0.9 & $1.09(0.63$ to 1.91$)$ & 0.562 \\
\hline Workplaces & 510 & 78.8 & 581 & 64.5 & 18.1 & $0.46(0.30$ to 0.70$)$ & 0.015 \\
\hline Restaurants & 629 & 85.3 & 745 & 75.1 & 12.0 & $0.49(0.26$ to 0.91$)$ & 0.038 \\
\hline Hotels & 188 & 83.4 & 230 & 75.6 & 9.4 & $0.67(0.47$ to 0.96$)$ & 0.041 \\
\hline Cafes/bars/nightclubs & 298 & 90.5 & 333 & 89.7 & 0.9 & $1.09(0.31$ to 3.80$)$ & 0.804 \\
\hline Amusement parks & 425 & 66.4 & 562 & 63.7 & 4.1 & $0.85(0.48$ to 1.50$)$ & 0.349 \\
\hline Waiting room of transport vehicles & 542 & 48.6 & 680 & 49.9 & -2.7 & $1.05(0.43$ to 2.54$)$ & 0.838 \\
\hline \multicolumn{8}{|l|}{ No ban } \\
\hline Home & 882 & 91.0 & 877 & 89.4 & 1.8 & $0.78(0.51$ to 1.21$)$ & 0.138 \\
\hline
\end{tabular}

smoking behaviors in full smoking ban places, especially among cultural venues and public transport vehicles. Consistent with previous studies [14-16], it is disappointing that smoking behaviors in these venues were not eliminated, but were still at a high level after implementation of the legislation. It was noteworthy that smoking behaviors in government offices and stadiums started from a high level in the baseline survey (43-48 \%) and was still high in the evaluation survey (25-30 \%). This observation may be due to poor compliance with the smoke-free legislation in these venues. More disappointing was that smoking behaviors in partial smoking ban places (89.6\% vs $90.4 \%)$ were still remarkably high after the implementation of a partial smoke-free legislation, due to the permissiveness of setting smoking rooms in these places. Notably, very few respondents (1-2 \%) reported smoking in workplaces, pubs, cafes or other enclosed public places in England after the implementation of comprehensive smoke-free legislation covering all enclosed public places and workplaces [17].

It is quite disappointing from a public health point of view, given that in both types of venues there were only small decreases of smoking in Guangzhou following the smoke-free legislation. One of the important reasons is that the Guangzhou government did not introduce a comprehensive smoke-free legislation since policymakers regarded the implementation of a partial smoke-free law as more feasible and practical in Guangzhou than a total ban. To note, a full smoking ban implemented in certain venues produced comparatively low smoking rates (10.7\%-48.3\%), while venues with a partial smoking ban revealed high smoking rates (48.6 \%-90.5\%), indicating an unwillingness of the policymakers to implement tougher policies. The effectiveness of a smoke-free legislation also required enforcement efforts and compliance from smokers and managers in venues. In Guangzhou, the law enforcement departments, tasked with smoking control, have been ineffective in their efforts. To our surprise, no one (including smokers and managers in the venues) was fined until May 2011, 9 months after the implementation of a smoke-free legislation. This study showed high rates of smoking in public places during the last 2 weeks, indicating low compliance with the smoking regulation. Therefore, increasing the compliance among smokers is the first step with a possible solution to include increasing the fine amount which is only RMB $¥ 50$ (US \$7.8) according to the current legislation. In addition, the managers in venues should take the opportunity to educate staff and enforce the mandate. An extensive and growing body of literature has shown that 
smoke-free policies have no economic impact on restaurants, pubs and other segments of the hospitality industry $[18,19]$. Findings from the present study, along with the published findings $[5,6,10,15]$, indicate that a partial smoke-free legislation has had a weak impact on smoking cessation, but a comprehensive smoke-free legislation can substantially attenuate smoking prevalence without having negative economic impacts on the local businesses.

It was noteworthy that the implementation of a smoke-free legislation in Guangzhou did not lead to more smoking behaviors in homes. This finding is in agreement with the previous associations observed between smoke-free public places and a reduction in smoking practices at home [17, 20-22], and suggest that smoke-free public places did not lead to displacement of smoking from public places into homes. In addition, findings from the international tobacco control policy evaluation project in Europe and America also suggested that smoke-free public places facilitated rather than inhibited the introduction of smoke-free homes [20, 21]. These results supported the social diffusion hypothesis that more restrictive rules regarding smoking in public places would increase the likelihood that individuals would adopt voluntary home smoking restrictions [20]. The rate of smoking in homes in our study (from $91.0 \%$ to $89.4 \%$ ) was much higher than those found in Albania (from $48 \%$ to $33 \%$ ) and England (from $65 \%$ to $55 \%$ ) $[10,17]$. These findings further add support to the enactment of comprehensive smoke-free legislation in public places, and at the same time highlighted the urgent need for educational interventions and campaigns promoting smoking cessation at home and voluntary changes in home smoking rules, especially among those households with infants, children, and adult non-smokers.

Previous studies found that the implementation of the comprehensive smoke-free legislation in England did not have a substantial impact on smoking prevalence in adults $[17,23]$. Despite the implementation of new tobacco control policies in Albanian, the smoking prevalence among males did not decrease, and smoking rates among females in general and in males aged 18-29 years continued to grow [10]. However, results from the 2002 to 2008 National Surveys from the US Census Bureau indicated that smoke-free laws and state tobacco control programs were effective strategies for curbing youth smoking [24]. Consistent with the above US study, the present study found that the reduction in the proportion of daily smokers was significant among 15-24 year olds for both genders, suggesting that a smoke-free legislation in Guangzhou is an effective strategy for curbing youth smoking. However, longer follow-up time may be needed to detect trends over time.

Previous research indicates that the implementation of comprehensive smoke-free legislation in Ireland and
England had positive effects on quit attempts and quit successes respectively, and a partial smoke-free legislation in the Netherlands had no effect on quit attempts or quit successes $[16,25]$. In Guangzhou, the quit ratios in most age groups increased after the implementation of a smoke-free legislation, but the quit ratios remained low compared to those in the countries with advanced tobacco control policies. The quit ratio was only $17.9 \%$ in our evaluation survey, which was much lower than the $51.8 \%$ found in the United States [26]. A study conducted in Hong Kong has suggested that smoke-free legislation that did not result in high rates of smoking cessation might displace smoking into homes [27]. Therefore, introduction of free tobacco cessation services, which are not currently available in Guangzhou, is urgently needed. In addition, quit rates might be further increased through better enforcement of the advertising bans and smoke-free legislation, as well as increasing the tax on cigarettes [10].

This study processes two strengths. The surveys were based on probability-based samples using standardized questions and allowed us to evaluate the different impacts of smoke-free legislation on smoking behaviors in full, partial and no smoking ban places at the same time. Additionally, to account for sample design and weighting in the estimation procedures, the statistical analyses were conducted with weighted data. However, some limitations should be considered when interpreting our results. First, the information was based on self-reports, and the findings may be susceptible to some bias. However, estimates obtained from population-based surveys that use self-reports are generally valid, apart from when there is a high demand for abstinence [28]. Second, the use of repeated cross-sectional data to assess the effectiveness of the smoke-free legislation may introduce bias, given that there may be differences in respondents between the two surveys. However, no significant differences in demographic characteristics (e.g., age and gender) were observed, and weighted data were used to adjust for the differences. Third, we found no significant differences between participants and non-participants in terms of sex, but the differences of age and smoking were uncertain since age and smoking were unable to be obtained from non-participants. This may have impacted the results for potential selection bias. Finally, this study lacks data to measure sufficiently what trends in smoking prevalence might have been in the absence of smoke-free legislation. Several national surveys conducted in China have indicated that in absence of a national smoke-free legislation, the smoking prevalence among adolescents had increased in the last decade in China [29-32]. Additionally, before the implementation of smoke-free legislation in Guangzhou, smoking prevalence among young women in this city increased from $1.2 \%$ in 2008 [33] to $2.6 \%$ in 
our baseline survey. This trend of escalation in smoking prevalence in Guangzhou and at a national level in China in the last decade suggests that the reduction in smoking prevalence observed in our 2011 sample is likely due to the implementation of smoke-free legislation in 2009.

\section{Conclusion}

In conclusion, the partial smoke-free legislation implemented in Guangzhou, China has some effect on curbing smoking behaviors in places with a full smoking ban (such as cultural venues, public transport vehicles and government offices), reducing daily smoking prevalence in youth, and increasing the quit ratios in most age groups. However, smoking behaviors in public places and homes were still high and the quit ratios remained low after the implementation of a partial smoke-free legislation. These findings point out the urgent need for a comprehensive smoke-free legislation covering all public places in Guangzhou. Simultaneously, educational interventions and campaigns promoting smoking cessation and adoption of voluntary smoke free-home policies need to occur.

\section{Competing interests}

The authors declare that they have no competing interests.

\section{Authors' contributions}

$X H Y$ and $Y Y$ planned the paper, carried out the statistical analyses, interpreted the data and drafted the manuscript. WL, SDC, ZJY, YHG, XY, SDZ, and ZWZ substantially contributed to the conception of the paper and to the interpretation of the data. In addition, all coauthors revised drafts critically for important intellectual content, and all authors reviewed and approved the final manuscript.

\section{Authors' information}

Not applicable.

\section{Acknowledgments}

This work was supported by the Bloomberg Philanthropies' tobacco control programme (No. U-China-3-02).

\section{Author details}

'Department of Epidemiology and Biostatistics, School of Public Health, Guangdong Pharmaceutical University, Guangzhou, China. ${ }^{2}$ Guangzhou Association on Tobacco Control, Guangzhou, China. ${ }^{3}$ College of Public Health, East Tennessee State University, Johnson, USA.

Received: 9 December 2014 Accepted: 25 September 2015 Published online: 29 September 2015

\section{References}

1. WHO. WHO report on the global tobacco epidemic: 2008. Geneva: World Health Organization; 2008. Available at: http://apps.who.int/iris/bitstream/ 10665/43818/1/9789241596282_eng.pdf. Accessed may 15, 2014.

2. WHO. WHO report on the global tobacco epidemic: 2011. Geneva: World Health Organization; 2011. Available at: http://apps.who.int/iris/bitstream/ 10665/44616/1/9789240687813_eng.pdf. Accessed may 20, 2014.

3. GATS Collaborative Group. Tobacco use in 3 billion individuals from 16 countries: an analysis of nationally representative cross-sectional household surveys. Lancet. 2012;380(9842):668-79.

4. Gu D, Kelly TN, Wu X, Chen J, Samet JM, Huang JF, et al. Mortality attributable to smoking in China. N Engl J Med. 2009;360(2):150-9.

5. Gleich F, Mons U, Po" tschke-Langer M. Air contamination due to smoking in German restaurants, bars, and other venues - Before and after the implementation of a partial smoking ban. Nicotine Tob Res. 2011;13(11):1155-60.

6. Naiman A, Glazier R, Moineddin R. Is there an impact of public smoking bans on self-reported smoking status and exposure to secondhand smoke? BMC Public Health. 2011;11:146.

7. MJ L' p, Nebot M, Schiaffino A, Pérez-Ríos M, Fu M, Ariza C, et al. Two-year impact of the Spanish smoking law on exposure to secondhand smoke: Evidence of the failure of the 'Spanish model'. Tob Control. 2012;21(4):407-11.

8. Ferrante D, Linetzky B, Virgolini M, Schoj V, Apelberg B. Reduction in hospital admissions for acute coronary syndrome after the successful implementation of $100 \%$ smoke-free legislation in Argentina: A comparison with partial smoking restrictions. Tob Control. 2012;21(4):402-6.

9. Ye X, Yao Z, Gao Y, Xu Y, Xu Y, Zhu Z, et al. Secondhand smoke exposure in different types of venues: before and after the implementation of smoke-free legislation in Guangzhou, China. BMJ Open. 2014;4(2):e004273.

10. Zaloshnja E, Ross H, Levy DT. The impact of tobacco control policies in Albania. Tob Control. 2010;19(6):463-8.

11. Huang J, Zheng R, Emery S. Assessing the impact of the national smoking ban in indoor public places in China: evidence from quit smoking related online searches. PLoS One. 2013;8(6):e65577.

12. Macy JT, Middlestadt SE, Seo DC, Kolbe L, Jay SJ. Applying the Theory of Planned Behavior to explore the relation between smoke-free air laws and quitting intentions. Health Educ Behav. 2012;39(1):27-34.

13. Brown A, Moodie C, Hastings G. A longitudinal study of policy effect (smoke-free legislation) on smoking norms: ITC Scotland/United Kingdom. Nicotine Tob Res. 2009;11(8):924-32.

14. Edwards R, Thomson G, Wilson N, Waa A, Bullen C, O'Dea D, et al. After the smoke has cleared: evaluation of the impact of a new national smoke-free law in New Zealand. Tob Control. 2008;17(1):e2.

15. Thrasher JF, Swayampakala K, Arillo-Santillán E, Sebrié E, Walsemann KM, Bottai M. Differential impact of local and federal smoke-free legislation in Mexico: a longitudinal study among adult smokers. Salud Publica Mex. 2010;52 Suppl 2:5244-53.

16. Nagelhout GE, de Vries H, Boudreau C, Allwright S, McNeill A, van den Putte $B$, et al. Comparative impact of smoke-free legislation on smoking cessation in three European countries. Eur J Public Health. 2012;22(Suppl1):4-9.

17. Lee JT, Glantz SA, Millett C. Effect of smoke-free legislation on adult smoking behaviour in England in the 18 months following implementation. PLoS One. 2011;6(6):e20933.

18. Melberg HO, Lund KE. Do smoke-free laws affect revenues in pubs and restaurants? Eur J Health Econ. 2012;13(1):93-9.

19. Scollo M, Lal A, Hyland A, Glantz S. Review of the quality of studies on the economic effects of smoke-free policies on the hospitality industry. Tob Control. 2003;12(1):13-20.

20. Borland R, Yong HH, Cummings KM, Hyland A, Anderson S, Fong GT. Determinants and consequences of smoke-free homes: findings from the international tobacco control (ITC) four country survey. Tob Control. 2006;15(Suppl3):iii42-50.

21. Mons U, Nagelhout GE, Allwright S, Guignard R, van den Putte B, Willemsen $M C$, et al. Impact of national smoke-free legislation on home smoking bans: findings from the International Tobacco Control Policy Evaluation Project Europe Surveys. Tob Control. 2013;22(e1):e2-9.

22. Bhaumik S. Ban on smoking in workplaces in India has led to more smoke free homes. BMJ. 2013;346:f2186.

23. Elton PJ, Campbell P. Smoking prevalence in a north-west town following the introduction of Smoke-free England. J Public Health. 2008:30(4):415-20.

24. Farrelly MC, Loomis BR, Han B, Gfroerer J, Kuiper N, Couzens GL, et al. A comprehensive examination of the influence of state tobacco control programs and policies on youth smoking. Am J Public Health. 2013;103(3):549-55.

25. Hackshaw L, McEwen A, West R, Bauld L. Quit attempts in response to smoke-free legislation in England. Tob Control. 2010;19(2):160-4.

26. Centers for Disease Control and Prevention: Number of smokers and number of smokers who have quit. Available at: http://www.cdc.gov/tobacco/ quit_smoking/how_to_quit/you_can_quit/alone/.htm. Accessed may 20, 2014.

27. Ho SY, Wang MP, Lo WS, Mak KK, Lai HK, Thomas GN, et al. Comprehensive smoke-free legislation and displacement of smoking into the homes of young children in Hong Kong. Tob Control. 2010;19(2):129-33.

28. Jung-Choi KH, Khang YH, Cho HJ. Hidden female smokers in Asia: a comparison of self-reported with cotinine-verified smoking prevalence rates 
in representative national data from an Asian population. Tob Control. 2011;21(6):536-42.

29. Ho MG, Ma S, Chai W, Xia W, Yang G, Novotny TE. Smoking among rural and urban young women in China. Tob Control. 2010;19(1):13-8,

30. Yang G, Fan L, Tan J, Qi G, Zhang Y, Samet JM, et al. Smoking in China: findings of the 1996 national prevalence survey. JAMA. 1999;282(13):1247-53.

31. Yang G, Ma J, Chen AP, Brown S, Taylor CE, Samet JM. Smoking among adolescents in China: 1998 survey findings. Int J Epidemiol. 2004;33(5):1 103-10.

32. Johnson CA, Palmer PH, Chou CP, Pang Z, Zhou D, Dong L, et al. Tobacco use among youth and adults in Mainland China: the China seven cities study. Public Health. 2006;120(12):1156-69.

33. Lei $C, X u Y X, X u Y$, Ying CM, Yang Y. Cross-sectional study of tobacco use of female high school and college students in Guangzhou. Chin J Sch Health. 2013;34(6):651-4

\section{Submit your next manuscript to BioMed Central and take full advantage of:}

- Convenient online submission

- Thorough peer review

- No space constraints or color figure charges

- Immediate publication on acceptance

- Inclusion in PubMed, CAS, Scopus and Google Scholar

- Research which is freely available for redistribution 